Reseña de libro:

\title{
El régimen de Anastasio Somoza, 1936-1956
}

\author{
de Knut Walter
}

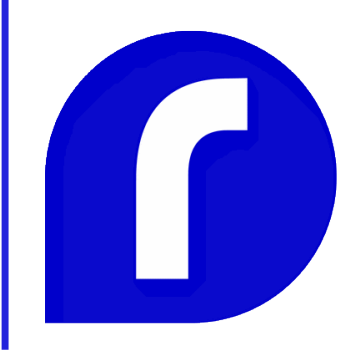

Knut, Walter. El régimen de Anastasio Somoza: 1936-1956. Managua:
Instituto de Historia de Nicaragua y Centroamérica, Universidad
Centroamericana, 2004.

\begin{abstract}
Jenyel Contreras Guzmán
Nicragüense Costarricense. Socióloga. Máster en Evaluación de Programas y Proyectos de Desarrollo, estudiante del Doctorado en Ciencias Sociales sobre América Central en la Universidad de Costa Rica (Costa Rica). Docente e investigadora en dicha universidad.

Correo electrónico: jenyel.contreras@ucr.ac.cr. ORCID: 0000 0002 6835 9920
\end{abstract}

\section{Karla Salazar Sánchez}

Costarricense. Psicóloga. Máster en Ciencia Política, Universidad Federal de Pernambuco, Brasil y Máster en Criminología, Universidad Estatal a Distancia, Costa Rica. Investigadora de la Facultad Latinoamericana de Ciencias Sociales - Sede Costa Rica. Estudiante del Doctorado en Ciencias Sociales sobre América Central en la Universidad de Costa Rica.

Correo electrónico: ksalazar@flacso.or.cr ORCID: 0000 0002 6835 9920

En "El régimen de Anastasio Somoza, 1936-1956" Knut Walter hace un recorrido historiográfico y de descripción densa, por los principales elementos políticos, económicos y sociales que forjaron el escenario para que se instalara y consolidara el régimen somocista durante veinte años en Nicaragua. Para esto, inicia su obra con un capítulo introductorio en el que revisa los objetivos del Estado y argumenta que, para el caso de Nicaragua, la formación del Estado moderno encontró sus cimientos en el régimen somocista a partir de los cambios que éste instauró en el sistema político. La primera transformación remite a la coalición policlasista del régimen en asoció con empresarios, comerciantes y burócratas gubernamentales. El segundo cambio da cuenta del fortalecimiento de las instituciones estatales y la capacidad de adaptación a los distintos niveles de estatidad. El autor recupera como elemento central el nivel de legitimidad alcanzado por el régimen, el cual recurrió a la fuerza solo en momentos de crisis política. Para profundizar en estos elementos, Walter realiza su análisis partiendo de al menos tres enfoques, a saber: el de actores políticos; el del desarrollo y el de la diferenciación institucional que potenciaron el crecimiento agroexportador; y el de las fisuras sociales y políticas de dicho modelo. 
Además de la introducción, el libro se estructura en seis capítulos. El primero revisa la sociedad y la política en Nicaragua antes de 1930, retomando elementos de la estructura económica y de las fracturas sociales internas que caracterizaron tal época, poniendo énfasis en los conflictos entre las dos agrupaciones políticas dominantes, los liberales de León y los conservadores de Granada, derivados de las luchas por el control del gobierno del Estado. El segundo capítulo dice de los orígenes de la dictadura, para lo cual fueron esenciales cuatro elementos que posibilitaron su llegada a la presidencia, a saber: el asesinato de Sandino y el debilitamiento de su movimiento -que en términos estrictamente militares y políticos se constituyó como un fenómeno regional del norte del país- a partir del acuerdo de Tipitapa de 1927; el que la Guardia Nacional estuviera bajo la dirección de Somoza, producto directo de la intervención de Estados Unidos y que fuera una fuerza poderosa en un país que en gran medida había sido desarmado en los acuerdos de Tipitapa; la promoción de la campaña política de Somoza, así como sus estrategias preelectorales; y la política del "Buen Vecino" a partir de la cual Washington redujo considerablemente su intervención en Nicaragua, la cual había sido consolidada durante el protectorado de 1910 a 1927.

Walter llama la atención sobre cómo durante los inicios del somocismo no era evidente su intención de convertirse en un poder económico, a través de la apropiación de los recursos del Estado y crear de esta forma un enorme imperio empresarial y familiar.

En el tercer acápite Walter centra su atención en la toma de poder por parte de Somoza en 1937, así como las distintas reformas financieras, fiscales, económicas y bancarias que fue implementando, a través de las cuales aumentaba su poder económico, tal fue el caso de la nacionalización del ferrocarril ese mismo año, uno de los negocios más rentables del país y el cual se colocó bajo el control directo de Somoza. Así como las reformas constitucionales y políticas que le permitieron cada vez un mayor control del gobierno central y municipal, el cual se extendió más allá del nombramiento de alcaldes, regidores, sindicatos y tesoreros, ya que en 1935 el gobierno se arrogó la potestad de aprobar los presupuestos anuales de los consejos municipales, siendo que Somoza además dispuso supervisar las finanzas municipales, aprobar el presupuesto de ingresos y gastos, autorizar todos los contratos firmados por las municipalidades con empresas privadas así como todas las obras públicas que se proponían realizar.

En este apartado se destaca además el crecimiento burocrático del Estado, en donde el empleo público amplió la clientela política del régimen e incidió directamente en el peso relativo de las fuerzas políticas del país.

En el cuarto capítulo el autor revisa las crisis que surgen en Nicaragua en 1944 ante la posible reelección de Somoza, a partir de las protestas que surgieron de manera espontánea y con organización apresurada, y que involucró principalmente a grupos urbanos dirigidos por políticos y activistas de clase media, con escaso contacto con las masas. Sin embargo, por primera vez, 
la oposición se manifestó en las calles, y la legitimidad misma del Estado se vio cuestionada. No obstante, en este punto Walter llama la atención sobre un aspecto central, el que las manifestaciones de protestas no deben interpretarse como un rechazo a la organización fundamental del Estado, sino más bien al régimen somocista, aspecto este clave para comprender adecuadamente las particularidades del Estado nicaragüense, así como la continuidad del régimen, ya que es hasta 1961 con la conformación del Frente Sandinista de Liberación Nacional (FSLN) en donde por primera vez se desarrolla una posición político - ideológica clara "anti-sistema".

En este punto la legitimidad estaba debilitada y se recurrió a medios coercitivos para retomar el control, utilizando a los soldados y grupos de choque para controlar las manifestaciones callejeras, así como el encarcelamiento de opositores y manifestantes. Además, la represión se fue institucionalizando con el control de la prensa y de las relaciones entre el capital y el trabajo.

Este episodio dio como resultado las elecciones fraudulentas de 1947 siendo electo Leonardo Argüello. En este momento, si bien Somoza ya no era presidente, mantenía el control del Estado a través de la Guardia Nacional y del Partido Liberal.

En el quinto acápite, el autor analiza las alianzas del régimen establecidas con los liberales y conservadores civilistas suscitadas por la falta de legitimidad del régimen ante el golpe de estado efectuado contra Argüello. Por un lado, estratégicamente firma el "Pacto de los Generales", mediante el cual establece una alianza con Emiliano Chamorro líder de la oposición conservadora, sin que esto implicara un cambio sustantivo a nivel de Estado ni en términos de su poder. Por otro lado, Somoza orientó su preocupación de desarrollo económico a la mejora de la eficiencia de la burocracia y a la creación de nuevas instituciones gubernamentales para fortalecer el apoyo del sector público a la empresa privada. Las relaciones entre el régimen y el sector privado también se caracterizaron por momentos de tensión y conciliación, pero nunca llegaron a una ruptura total.

En el capítulo sexto el autor centra su análisis en el enfoque de actores, para lo cual hace una revisión de defensores y opositores del régimen. Señala Walter que, a pesar de los acuerdos firmados, el Partido Conservador, los Liberales Independientes y los exiliados seguían siendo oposición e implicaban para el somocismo un esfuerzo constante para mantener el poder coercitivo, lo cual se lograba mediante el control de la Guardia Nacional, su gran aliada. El autor distingue entre tres tipos de oposición: la oposición cívica, la oposición en el exilio y la oposición armada. Todos estos frentes podían actuar en conjunto según el momento; no obstante, su debilidad se encontraba en la falta de una estrategia sólida común. Este capítulo finaliza con el asesinato de Somoza en 1956 por parte de Rigoberto López Pérez, lo cual más allá de socavar el poder del régimen, implicó una reacción represiva y la toma de poder por parte de los hijos. Luis Somoza concluyó el periodo presidencial y Somoza Debayle asumió la dirección de la Guardia Nacional. 
Finalmente, el texto permite identificar que los principales elementos que garantizaron la permanencia del régimen podrían resumirse en tres grandes aspectos. Primero, el manejo estratégico de la fuerza para garantizar el poder, pero no debilitar su legitimidad. Segundo, la innovación institucional y la respuesta ante problemas políticos y administrativos, de modo que a pesar de la crisis se registraba cierto nivel de desarrollo económico en el país y se limitaba la imposición de impuestos que ahogaran al sector empresarial. Tercero, el establecimiento de alianzas y acuerdos con la oposición que le permitía tener un control sobre las mismas coaliciones que tenía en su contra, sumado a la debilidad de esas facciones opositoras.

Cabe agregar que el imperio económico que fue desarrollando la familia Somoza sumaba a su poder político el poder económico. Dado el control generalizado de Somoza en las distintas instituciones gubernamentales, él ponía a servicio de sus negocios el aparato público. Esta sería una característica diferenciadora de este régimen en relación con las otras experiencias de esta naturaleza a nivel latinoamericano, de la cual se sirvió muchos beneficios, pero que constituyó un factor clave en la revolución que llevara a acabar con el régimen.

En fin, el texto de Walter permite un acercamiento detallado a la historia del régimen mientras Anastasio Somoza se mantuvo en el poder y expone con mucha claridad los elementos centrales para entender las condiciones que propiciaron no solo que asumiera el poder, sino que lo mantuviera durante veinte años. Más aún, permite un acercamiento a la conformación y maduración del Estado moderno nicaragüense, a sus contradicciones y continuidades.

\section{Bibliografía}

Knut, Walter. El régimen de Anastasio Somoza: 1936-1956. Managua: Instituto de Historia de Nicaragua y Centroamérica, Universidad Centroamericana, 2004. 